\title{
Problematic smartphone use relationship with pathological personality traits: Systematic review and meta-analysis
}

\author{
Lucas de Francisco Carvalho, Catarina Possenti Sette, \& Bárbara Letícia Ferrari \\ Universidade São Francisco, São Paulo, Brazil
}

\begin{abstract}
The present study aimed to investigate relationships between problematic use of smartphone and pathological personality traits. To do so, we performed a systematic review and meta-analysis when sufficient information was presented. The literature search was conducted based on a search strategy including the keywords "smartphone" and "personality". Variations were not included as we seek to increase the breadth of the search. Random effects models were used to generate standardized coefficient for meta-analysis. In total, the present study included 5 papers covering 6.096 participants. Our findings indicated a scarcity of studies meeting the criteria used, but evidence regarding the relationship between problematic use of smartphone and neuroticism and impulsivity traits were found. Meta-analysis using levels of problematic use of smartphone and neuroticism and impulsivity measures showed a significant and small to moderate effect size, with an observed heterogeneity $\left(I^{2}\right)$ equal to 97.26\% (impulsivity) and 58.89\% (neuroticism). More research should be carried out in the area, allowing the accumulation of evidence considering several personality pathological traits. The impulsivity and neuroticism traits should be further investigated, including studies with psychiatric samples. Future studies should seek to establish a standard for study design and assessment tools to be used.
\end{abstract}

Keywords: Personality disorders; smartphone; addiction; systematic review; meta-analysis

\section{Introduction}

According to recent statistical reports, the number of smartphone users estimated for 2017 should exceed 2.3 billion. Users are expected to exceed 5 billion over the next two years. Among the countries with the largest number of users are China and the US (Statista Inc., 2016), and the accelerated growth of smartphone users has been observed in several countries (e.g., USA, Germany and Malaysia), representing the most rapidly adopted technology in human history (Rainie \& Wellman, 2012). The use of smartphones has become something essential in many people's lives (Lee, Chang, Lin, \& Cheng, 2014; Lee et al., 2016).

The dominance of the smartphone in everyday life is evident (Montag et al., 2015), and it is probably related to the possibility of instant and almost uninterrupted communication between users (Radovic et al., 2016; Sarwar \& Soomro, 2013), as well as access to online social networks and other activities, such as accessing e-mail, visualizing news, and using several applications (e.g. Global Positioning System (GPS) navigation). There is an expressive amount of studies investigating the activities performed by smartphone users (e.g. Montag et al., 2015; Oulasvirta, Rattenbury, Ma, \& Raita, 2012; Wang, Xiang, \& Fesenmaier, 2014). The use of smartphones can become excessive, compulsive and/or addictive, characterizing a problematic use of smartphone (e.g., Elhai, Dvorak, Levine, \& Hall, 2017; Saidon, Musa, Harun, \& Adam, 2016). In this study we performed a systematic review followed by metaanalysis, seeking to investigate the relationship between pathological personality traits and problematic smartphone use (PSU). 


\section{Theoretical Background}

Researchers have sought to know more about users who make harmful use of the smartphone, which has been called problematic smartphone use (PSU) (e.g., Kardefelt-Winther, 2014; Kuss, Griffiths, Karila, \& Billieux, 2014). Addiction, excessive use, and compulsive use are among the terms most frequently related to PSU (Demirci, Akgönül, \& Akpinar, 2015; Elhai et al., 2017), and are associated with several harmful conditions, such as poor sleep quality (Yogesh \& Priyanka, 2014), texting while driving (Cazzulino, Burke, Muller, Arbogast, \& Upperman, 2014), reduced work engagement (Lanaj, Johnson, \& Barnes, 2014), stress, low self-esteem (Wang, Wang, Gaskin, \& Wang, 2015), decrease in academic outcomes (Rozgonjuk, Saal, \& Täht, 2018; Samaha \& Hawi, 2016), psychological and biological stress/problems (Gutiérrez, Fonseca, \& Rubio, 2016; Lee at al., 2014), and psychopathology (Elhai et al., 2017), including anxiety and depression (e.g., Demirci et al., 2015; Kim, Seo \& David, 2015).

The link between psychopathology and PSU seems to be well established in the literature (e.g., Elhai et at., 2017; Jenaro, Flores, Gómez-Vela, González-Gil, \& Caballo, 2007; Koivusilta, Lintonen, \& Rimpelä, 2007; Montag et al., 2015), as PSU tends to imply negative impacts on mental health. There are theoretical framework trying to explain the associations between PSU and psychopathology, for instance, the Compensatory Internet Use Theory (CIUT; Kardefelt-Winther, 2014) provides explanation on variables that drive PSU behaviors, focusing on negative events and stressors that can motivate people to use and overuse technology (see Elhai et al., 2017; Elhai et al., 2018).

Accordingly, PSU characteristics resemble addiction-like behaviors and may share properties with Internet addiction and problematic Internet use as both are related to interpersonal interaction (Gutiérrez et al., 2016; Takao, Takahashi, \& Kitamura, 2009). Some studies have already presented evidence of the overlap between PSU and internet addiction (e.g. Kwon et al., 2013; Lachmann, Duke, Sariyska, \& Montag, 2017), including theoretical models aiming to explain the underlying processes to the development and establishment of the internet dependent use and specific apps, for example, The Interaction of Person-Affect-Cognition-Execution model (IPACE; Brand, Young, Laier, Wölfling, \& Potenza, 2016). The I-PACE model provides a theoretical framework, presenting mechanisms underlying the development and maintenance of internet-use disorders.

A diagnostic classification was recently proposed (Lin et al., 2016), considering problematic smartphone usage in the context of addiction, where this condition is often composed by compulsive behaviors, tolerance, withdrawal, and functional impairment. Three diagnostic criteria were proposed: symptoms (criterion A), functional impairment secondary to smartphone use (criterion B), and exclusion criteria to rule out manic episodes and obsessive-compulsive disorder (criterion C). The criterion A symptoms are: recurrent failure to resist the impulse to use the smartphone; withdrawal, manifested as a dysphoric mood, anxiety and irritability after a period without smartphone use; smartphone use for a period longer than intended; persistent desire and/or unsuccessful attempts to cut down or reduce smartphone use; excessive smartphone use and/or time spent on quitting smartphone use; and continued excessive smartphone use despite knowledge of having a persistent or recurrent physical or psychological problem resulting from smartphone overuse. The criterion B functional impairments are: excessive smartphone use resulting in persistent or recurrent physical or psychological problem; smartphone use in a physically hazardous situation (e.g., smartphone use while driving, or crossing the street), or having other negative impacts on daily life; smartphone use resulting in impairment of social relationships, school achievement, or job performance; and excessive smartphone use causes significant subjective distress, or is time consuming.

The described criteria are similar to those pointed out in a recent review study (Gutiérrez et al., 2016); however, in the review the aspects were more focused on the behavioral correspondence of PSU. The behavioral aspects are: problems and conscious use in dangerous situations or prohibited contexts; social and family conflicts and confrontations, as well as loss of interest in other activities; continuing behavior despite the negative effects and/or personal malaise it causes; harm, physical, mental, social, work, or family disturbances; difficulty controlling; frequent and constant checking of phone in very short periods of time with insomnia and sleep disturbances; tolerance; increase in use to achieve satisfaction or relaxation or to counteract a dysphoric mood; excessive use, urgency, need to be connected; need to respond immediately to messages, preferring the cell phone to personal contact; abstinence, dependence, craving; anxiety, irritability if cell phone is not accessible, and feelings of unease when unable to use it. 
Although previous criteria have been proposed (e.g., Gutiérrez et al., 2016; Lin et al., 2016), there is no consensus on the optimal criteria set respecting the PSU diagnostic and/or smartphone addiction, or even how the smartphone per se could be addictive. The majority of studies are cross-sectional (i.e., not experimental or quasiexperimental), including only college students or community samples, usually not covering clinical samples. These limitations must be accounted when reading scientific material and when outlining research (Kardefelt-Winther et al., 2017; Panova \& Carbonell, 2018).

In the context of addiction, several measures were developed to assess PSU (Lin et al., 2016), although it has been measured by scales of substance-related addiction symptoms (Elhai et al., 2017), and is typically related to exaggerated increase in smartphone use and habitual checking on missed calls (Lee at al., 2014; Lee at al., 2016; Takao et al., 2009). One example of measure of PSU used across different studies is the Smartphone Addiction Scale (SAS; Kwon et al., 2013) and the short version of the SAS also is used in different cultures (e.g. Haug et al. 2015; Lopez-Fernandez 2017; Rozgonjuk, Rosenvald, Janno, \& Täht, 2016). To better understand compulsive technology consumption, as well as PSU specifically, personality traits have been viewed as a relevant component (e.g., Montag et al., 2015; Mueller et al., 2011; Roberts \& Pirog, 2013; Takao et al., 2009).

Most of the studies relating PSU to personality traits focus on health personality traits, mainly using the Five-Factor model as basis (e.g., De Pasquale, Sciacca, \& Hichy, 2015; Demirhan, Randler, \& Horzum, 2016; Lane \& Manner, 2011; Lepp, Li, Barkley, \& Salehi-Esfahani, 2015; Montag et al., 2015; Toda, Ezoe, Mure, \& Takeshita, 2016; Ünal, Temizel, \& Eren, 2016). Although we can observe a significant amount of studies considering healthy personality traits, studies including or focusing on pathological personality traits are scarce. Although healthy and pathologic are arbitrary, pathological traits are maladaptive variants of the personality trait, that bring substantial impairment to the individual in several areas of his life, typically related to difficulties with the self and with interpersonal relationships (American Psychiatric Association, 2013; Millon, 2016). For instance, the self-confidence trait is related to the confidence someone has in himself/herself. Very high levels of this trait can configure a maladaptive expression, as grandiosity, characterized by inflated sense of self, arrogance, exaggerated need of recognition, and callousness. The small number of studies focusing on pathological personality traits or at least including measures to assess them (e.g., Kim et al., 2016; Roberts, Pullig, \& Manolis, 2015), contrasts with a reasonable amount of evidence showing the relationship between PSU and mental health (Karaaziz \& Keskindag, 2015; Saidon et al., 2016; Torous, Kiang, Lorme, \& Onnela, 2016).

As important as understanding the relationships between PSU and healthy personality traits, is to extend the knowledge about which pathological personality traits are most related to PSU. Considering that the pathological personality traits are related to expressive impairment in the interpersonal relationships and with the self (American Psychiatric Association, 2013), and with impairments to deal with the everyday demands (Millon, 2016), these traits can be understood as potentially causing conditions related to the abusive use of technology (e.g., Montag \& Reuter, 2017). Building on previous studies, we can access what is already known on the relationship between PSU and pathological personality traits, how much of this condition can be predicted from these traits, which pathological personality profiles are more likely to manifest PSU and, finally, which interventions are prone to be more effective in these cases.

In the present study, we sought to aggregate the evidence already presented in the literature about these relationships. The deepening of knowledge on associations can help in the improvement of the theoretical frameworks covering pathological traits and PSU behaviors, as well as in recognize pathological profiles more typically related to PSU, thus indirectly assisting in assessment and intervention. The objective of this research was to investigate relationships between PSU and pathological personality traits. To do so, we performed a systematic review and a meta-analysis when sufficient information was presented.

\section{Method}

As a first step, we registered the systematic review in the International prospective register of systematic reviews (PROSPERO 2016: CRD42016049875). The procedures used in this study were performed based on PRISMA guideline suggested for conducting a systematic review and meta-analysis (Moher, Liberati, Tetlaff, \& Altman, 2009). 


\section{Search Strategy}

As an initial step, we conducted a screening in September 2016. We searched the PsycInfo, PubMed, and Science Direct databases, focusing on peer-reviewed journals for the following terms: "smartphone" and "personality". Variations were not included as we intend to increase the extent of the search. We entered these terms in the title, abstracts, keywords or full texts. Complementarily, we also hand-searched the first 10 pages at Google Scholar.

\section{Eligibility Criteria}

First, we conducted a screening of the title and abstract of each paper selected from the search strategy. We included studies that provided empirical evidence of the relation between problematic smartphone use/smartphone addiction and pathological personality traits, as well as studies that: (1) involved adults aged 18 or older, (2) including a measurement of smartphone problematic use or addiction, and, (3) including a measure of personality disorders or pathological personality traits. In addition, as an exception, we maintained researches assessing the Neuroticism factor based on instruments measuring the Five-Factor Model, as this factor directly covers some dysfunctional behaviors (Costa \& McCrae, 1992). We excluded studies that (1) evaluated other aspects of the PSU and not directly problematic use or addiction (e.g. motivation, attitudes) and/or (2) included only smartphone assessment or pathological personality traits assessment. No study design, date or language limits were imposed on the search.

\section{Data Extraction}

Data were extracted using a standardized data extraction method by the authors. Paper managing was conducted using Mendeley Desktop version 1.16.1 for Windows. We distributed the papers in folders according to database, and then we proceeded to verification for duplicate papers. Discrepancies were solved by consensus. Reasons for the posteriori exclusion of studies that had been identified as relevant in the initial abstract searches were recorded. The authors independently reviewed titles and abstracts to select papers within the established inclusion criteria, and then, they read the selected articles, focusing mainly on Method and Results, considering the established inclusion criteria. As a final step, the authors read the papers again, full text, for qualitative syntheses to extract and synthesize the data for the purpose of systematic review. For systematic review, we extracted the following data: authors' name and year of publication, country of data collection, Journal's title, personality traits investigated, term used for problematic smartphone use, sample description, measures for PSU, measures for pathological personality traits, procedures for data collection, and main results. For the metaanalysis, we looked for any effect size (e.g., Pearson's $r$, Cohen's $d$ and Beta from regression) or descriptive data allowing the calculation of effect sizes; we also recorded the sample size.

\section{Quality Report Assessment, Bias Risk and Publication Bias}

As we did not find a quality report and a bias risk checklist narrowly adequate for the methodologies used in the papers' screened studies, two existing checklists were used as a basis. For quality report assessment: Strengthening the Reporting of Observational studies in Epidemiology (STROBE; von Elm et al., 2007); for bias risk: Critical Appraisal and Data Extraction for Systematic Reviews of Prediction Modeling Studies (CHARMS; Moons et al., 2014) guidelines and some keys were created according to the methods of the selected studies.

Based on that, we considered the following key items for quality report: title and abstract (title appropriate to the study scope and all the necessary elements were provided in the abstract), background/rationale (the scientific background and rationale for the investigation were presented), objectives (the aim was clearly presented, including any pre-specified hypotheses), study design (key elements of study design early in the paper were presented), setting (design was clearly described), participants (criteria for inclusion and exclusion of participants were reported), descriptive data (socio-demographic characteristics were described), data sources/measurement (how the variables of interest were measured and evaluated were described), description of instruments (instruments were clearly described), psychometric properties report (psychometric properties of the instruments were reported), study sample size (how the sample size was determined was explained), statistical methods (all statistical analyzes were clearly described), missing data (missing data were reported), description of results (results were clearly described), key results (study summarizes key results with reference to study objectives), 
limitation (at least the main limitations were considered), interpretation (all relevant results were discussed based on literature and presented a general interpretation of results considering objectives, limitations, results from similar studies, and other relevant evidence), generalizability (authors discuss the generalization of the results), funding (source of financing was reported), and journal impact (journal presented an impact factor of .75 or superior. This number refers to the mean of the Journal Rank Indicator, a measure of the journal's impact, and was calculated from Journal \& Country Rank (Scimago Lab, 2016) filtered by area (psychology) and year (2014), based on 1,044 journals). The score for all keys was zero if the study did not achieve the expected and 1 point was attributed if the study presented what was requested. The score ranged from zero to 20 points. For the interpretation of the scores we considered three levels of quality: zero to 10 points (poor); 11 to 14 points (moderate); 15 to 20 points (good), an arbitrarily established division, although stringent.

For bias risk, we considered the following key items: participants description (sufficient participants description was provided), sample size (sample size calculation/rationale was presented or $N \geq 200$ (we used G*Power3 software to sample size calculation based on correlation and $t$ test analyses, $p \leq .05$, effect size $=.20$, power $=.80$ )), missing data (missing data were reported), psychometric properties detailing (if a PSU (or related) measure was developed for the study, the authors verified the psychometric adequacy; if measures from literature were used, authors reported the psychometric properties), instruments (instruments were clearly described), statistical methods (statistical procedures were appropriately presented). For the total score, we attributed zero when the information was not adequate, and 1 point was given if the study presented what was requested. The score ranged from zero to 6 points. The same three levels of interpretation were considered: up to 50\% (poor); > 50\% to 70\% (moderate); > 70\% (good).

\section{Statistical Analysis}

Conducting meta-analysis in the present research was based in the robust literature in the field, including the cut off regarding the minimum number of studies enabling to carry on the procedure. As stated by Borenstein, Hedges, Higgins, and Rothstein (2009), two studies are enough to carry out a meta-analysis, although the limitations must be clarified depending on the size of the samples and methodology quality. According to previous findings (Davey, Turner, Clarke, \& Higgins, 2011), the median number of included studies was three, and 36\% of the meta-analyses included two studies only. Moreover, Turner, Bird and Higgins (2013) empirically found that two studies are sufficient, depending on studies characteristics.

In this review we used only cases in which an effect size was presented (e.g., $d, \beta$ or $r$ ) and cases where enough information was presented for the calculation of the effect sizes. All studies included in meta-analysis presented Pearson correlations ( $r$, even generated based on Cohen's $d$ ) or linear regression standardized $(\beta)$. For multiple regression, using multiple predictor variables, we used the procedure to transform $\beta$ in $r$ coefficient (Peterson \& Brown, 2005). The coefficients have been corrected for the $Z$ distribution, as $r$ does not have a normal distribution. The meta-analysis was conducted using the random model to estimate continuous effect size, as it was evidence of heterogeneity. To effect sizes (i.e., $r$ ) interpretations, we used empirical guidelines (Hemphill, 2003) among psychological studies as basis (<.20 (weak), .20 to .30 (moderate), and $>.30$ (strong)). All the analyses were performed in R software version 3.03 using metaphor package (Viechtbauer, 2017) and statistical significance was established at $p=.05$. We could not apply the publication bias verification using funnel plot and Egger's regression test since the number of studies considered in each analysis was relatively small (Rothstein, Sutton, \& Borenstein, 1996; Sutton \& Abrams, 2000).

\section{Results}

\section{Study Selection}

Using the previously described criteria and databases we identified 983 papers. The search using Google Scholar provided 100 additional publications. The correct amount identified after removing duplicates was 955. In the screening stage, based on the reading of titles and abstracts, most of the papers were excluded (95.6\%). The 41 remaining papers were fully verified and 36 of them were excluded. In most cases, the exclusion in the final selection was due to not using a measure assessing some aspect of problematic use of smartphone. The detailed process can be visualized in Figure 1. 


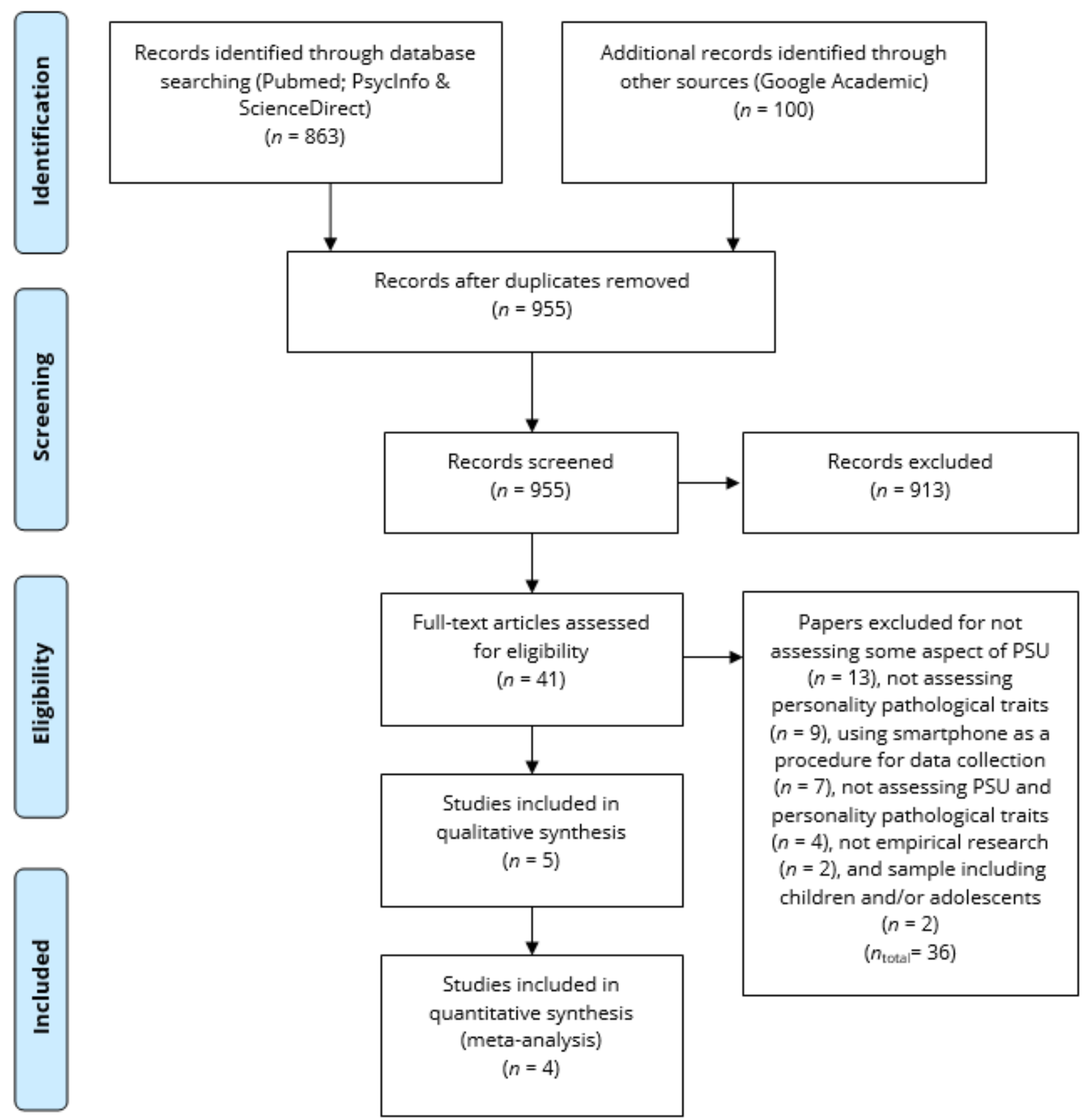

Figure 1. Flow diagram based on PRISMA. See the Supplementary Material with the 36 references excluded after full reading.

The mainly reason for studies exclusion was not assessing aspects of PSU, followed by not assessing pathological traits, and the specific use of smartphones in the study for data collection. We held 5 papers in the systematic review, encompassing 6,096 participants. For meta-analysis, 4 papers of the total were employed.

\section{Study Characteristics}

Table 1 presents more basic and initial data extracted and synthesized from the five studies. 
Table 1. Initial Descriptive Information of Studies Included in the Systematic Review and Meta-Analysis.

\begin{tabular}{|c|c|c|c|c|c|}
\hline Study & Authors (year) & Country & Journal & Personality trait & Term \\
\hline $9^{a}$ & $\begin{array}{l}\text { Roberts, Pulling, \& } \\
\text { Manolis (2015) }\end{array}$ & USA & $\begin{array}{l}\text { Personality and Individual } \\
\text { Differences }\end{array}$ & $\begin{array}{l}\text { Impulsivity and } \\
\text { Emotional } \\
\text { instability }\end{array}$ & $\begin{array}{l}\text { Cellphone } \\
\text { addiction }\end{array}$ \\
\hline
\end{tabular}

\begin{tabular}{|c|c|c|c|c|c|}
\hline $10^{\mathrm{a}}$ & $\begin{array}{l}\text { Mok, Choi, Kim, Choi, } \\
\text { Lee, Ahn, Choi, \& Song } \\
\text { (2014) }\end{array}$ & South Korea & $\begin{array}{l}\text { Neuropsychiatric Disease } \\
\text { and Treatment }\end{array}$ & $\begin{array}{l}\text { Psychoticism and } \\
\text { Neuroticism }\end{array}$ & $\begin{array}{l}\text { Smartphone } \\
\text { addiction }\end{array}$ \\
\hline $17^{a}$ & $\begin{array}{l}\text { Kim, Jeong, Cho, Jung, } \\
\text { Kwak, Rho, Yu, Kim, \& } \\
\text { Choi (2016) }\end{array}$ & South Korea & Plos ONE & Impulsivity & $\begin{array}{l}\text { Smartphone } \\
\text { addiction }\end{array}$ \\
\hline $35 * a$ & Bianchi \& Phillips (2005) & Australia & $\begin{array}{l}\text { Cyberpsychology \& } \\
\text { Behavior }\end{array}$ & $\begin{array}{l}\text { Psychoticism and } \\
\text { Neuroticism }\end{array}$ & $\begin{array}{l}\text { Problematic } \\
\text { use }\end{array}$ \\
\hline $37^{a}$ & $\begin{array}{l}\text { Pearson \& Hussain } \\
(2015)\end{array}$ & United Kingdom & $\begin{array}{l}\text { International Journal of } \\
\text { Cyber Behavior, } \\
\text { Psychology and Learning }\end{array}$ & $\begin{array}{l}\text { Narcissism and } \\
\text { Neuroticism }\end{array}$ & $\begin{array}{l}\text { Smartphone } \\
\text { addiction }\end{array}$ \\
\hline
\end{tabular}

\footnotetext{
Note: Author (year) = author of papers and year of publication; Country = country where data collection was proceeded; Journal = title of the Journal of the paper; Personality trait = personality trait justifying the inclusion of the paper in the systematic review; Term = term used in the paper to refer to PSU. *= study focused on mobile phone.

a = paper included in meta-analysis.
}

All papers were published by multiple authors and $60 \%$ by at least three authors; and only one author appeared in more than one paper. We observed that the authors were from mental health departments $(n=15$; including psychiatry, psychology and an addiction institute), engineering $(n=3)$, marketing $(n=3)$, medical informatics $(n=$ 2), and social welfare $(n=1)$. Practically all publications are from the $2010 \mathrm{~s}$, but one from 2005 . South Korea is the most frequent country of data collection, but there are countries from four continents. None of the journals presented more than one publication and two of them are related to the personality and technology field. Regarding personality traits, impulsivity, neuroticism, and psychoticism were the most frequent; however, the psychoticism trait was investigated only in one paper (paper number 10) and was not considered in the results presented in another paper (paper number 35). So, we cannot consider that the psychoticism trait appeared in more than one paper, in terms of results. Moreover, only one paper was focused on some personality disorder (i.e., narcissism personality disorder). We also observed that all the studies presented an objective directly and explicitly related to verifying the relationship between some PSU and pathological personality traits. Also, as it can be seen in the last column, the PSU term used included the "addiction" word in almost all cases. Table 2 presents more detailed information regarding methodological issues.

Most studies $(n=4)$ comprised a sample composed predominantly of females and university students; in $60 \%$ of the studies participants had an average age under 30. All the instruments administered were self-report measures, for both PSU and pathological personality traits. None of the papers used the same measure to assess PSU, and in one study the authors developed the instrument. Differently, two personality trait scales were more frequent, the Barratt Impulsiveness Scale (BIS) and the Eysenck Personality Questionnaire (EPQ), used in two papers. Most of the data collection was done online, some of which were by a professional polling company (paper 17), by email (paper 9) or made available in an online social network (paper 37). In the other two papers, data collection was done in person at the university, and by sending the questionnaires to the participants via mail. Despite the method of data collection, all studies had a cross-sectional design, and none of the papers specified the smartphone operating system (e.g., IOS, Android).

Some studies correlated the variables of PSU to personality pathological traits, some tried to predict variables by regression analysis, and some, compared groups. In the case of comparisons between groups (papers 10 and 17), significant differences were found for almost all groups, but the same was not observed from the correlations and predictive coefficients in the studies that used correlation and regression (papers 9, 17, 35, and 37). Specifically, in regression analyzes (papers 17, 35, and 37) using several predictor variables at the same time (e.g., sex, age, low 
self-esteem, five-factor model factors, length of smartphone ownership, NPI), we can notice an evident decrease in predictive loads $(\beta)$.

Table 2. Design and Methodological Description of Studies Included in the Systematic Review and Meta-analysis.

\begin{tabular}{|c|c|c|c|c|c|c|}
\hline Study & Sample & Population & $\begin{array}{l}\text { Measures for } \\
\text { smartphone }\end{array}$ & $\begin{array}{l}\text { Measures for } \\
\text { personality }\end{array}$ & $\begin{array}{l}\text { Data } \\
\text { collection }\end{array}$ & Results \\
\hline 9 & $\begin{array}{l}N=346 \\
51 \% \\
\text { female }\end{array}$ & $\begin{array}{l}19-24 ; M=21 \\
\text { college } \\
\text { students }\end{array}$ & $\begin{array}{l}\text { four-item Cell } \\
\text { phone } \\
\text { Addiction } \\
\text { Scale }^{b}\end{array}$ & $\begin{array}{l}\text { BIS; Seven } \\
\text { personality } \\
\text { factors }\end{array}$ & Online & $\begin{array}{l}r_{\text {attention impulsiveness*cellphone addiction }}=.12 ; \\
r_{\text {motor impulsiveness*cellphone addiction }}=.07 ; \\
r_{\text {non-planning impulsiveness*cellphone addiction }}=-.01 ; \\
r_{\text {emotional.instability }}{ }^{*} \text { cellphone addiction }=.17^{\mathrm{e}}\end{array}$ \\
\hline 10 & $\begin{array}{l}N=448 \\
60.3 \% \\
\text { female }\end{array}$ & $\begin{array}{l}\text { Male: } M= \\
21.80 ; \text { female: } \\
M=20.38 \\
\text { college } \\
\text { students }\end{array}$ & SAS & EPQ & In person & $\begin{array}{l}\text { \&: significant differences in } P(F=10.22)^{i} ; \\
L C 3^{f}>L C 2^{g}>L C 1^{h} ; \sigma^{f} \text { : didn't present } \\
\text { differences in } P ; \text {; } \text { : significant differences in } \\
N(F=8.38)^{i} ; L C 3^{f}=L C 2^{g}>L C 1^{h} ; \sigma^{f} \text { : differences } \\
\text { in } N(F=24.13)^{i} ; L C 3^{f}>L C 2^{h}>L C 1^{h} \text {. }\end{array}$ \\
\hline 17 & $\begin{array}{l}N= \\
4,854 \\
53 \% \\
\text { male }\end{array}$ & $\begin{array}{l}\text { Male: } M= \\
\text { 34.12; female: } \\
M=32.73\end{array}$ & K-SAPS & BIS; DDII & Online & $\begin{array}{l}\text { BIS: dgroupSAP vs groupNonSAP }=.70^{i}(t=17.22) ; \\
\text { DDII: dgroupSAP vs groupNonSAP }=.63^{i}(t=14.28) ; \\
\text { BDDII } \rightarrow \text { SAP }=0.08^{i}\end{array}$ \\
\hline 35 & $\begin{array}{l}N=195 \\
68 \% \\
\text { female }\end{array}$ & $M=36.07$ & $\begin{array}{l}\text { Mobile Phone } \\
\text { Use Surveyc }\end{array}$ & $\begin{array}{l}\text { EPQ-Revised } \\
\text { Short Scale }\end{array}$ & Mail & $\beta_{\mathrm{N}} \rightarrow$ smartphone problematic use $=.13^{\mathrm{j}}$ \\
\hline 37 & $\begin{array}{l}N=253 \\
71 \% \\
\text { female }\end{array}$ & $\begin{array}{l}17-68(M= \\
29.20) ; \\
35 \% \text { student; }{ }^{a}\end{array}$ & Young's (1996) & $\begin{array}{l}\text { NPI; Goldberg's } \\
\text { Big Five } \\
\text { personality }\end{array}$ & Online & $\begin{array}{l}\beta_{\mathrm{N}} \rightarrow \text { smartphone addiction }=.28^{\mathrm{i}} \\
\beta_{\mathrm{NPI}} \rightarrow \text { smartphone addiction }=.21^{\mathrm{i}}\end{array}$ \\
\hline
\end{tabular}

Note: $\mathrm{a}=$ the remaining were $8 \%$ health care, $7 \%$ education, $5 \%$ sales/marketing, $4 \%$ administration and science/technology, 3\% customer service and restaurant, $2 \%$ accounting/finance, architecture/design, construction, consulting and social service and 1\% arts/leisure/entertainment, beauty/fashion, management, operations and production; and 17\% ticked "other"; $b=$ the scale to evaluate smartphone already existed; $c$ = the scale was developed in the study; $d$ = used existing scale and added questions; e = we did not report the results concerning the path estimates; $f=L C 3$ (higher in smartphone addiction); $g=$ LC2 (moderate in smartphone addiction); $h=$ LC1 (lower in smartphone addiction); I = $p<.001$ (only in paper $9 p<.05$ ). SAP = Smartphone addiction predisposition; $\mathrm{N}=$ neuroticism; $\mathrm{P}=\mathrm{Psychoticism;}$ $\mathrm{j}=$ authors did not present results related to psychoticism trait in the paper.

\section{Quality Report and Bias Risk Assessment}

Table 3 presents the results from the scoring system for studies quality verification, including quality report and bias risk assessment. In each line the scores are presented for the five papers.

As we can see in Table 3, in the quality report assessment the studies ranged between moderate level (papers 9 and 35) and good level (papers 10, 17 and 37). In addition, none of the studies scored in study size (i.e., provides rationality on how they arrived at the study size) and funding (i.e., provides the source of funding and the role of the funders). On the other hand, in the bias risk assessment, all the studies reached a good level, showing a tendency for a low probability of bias risk in the publications. Only study 9 did not score on the keys Missing data and Psychometric properties detailing. Considering the 2 checklists, only study 9 presented lower scores and papers 10 and 17 obtained the highest scores.

\section{Meta-analysis: Impulsivity and Neuroticism Traits Relation to PSU Scores}

We conducted two meta-analyses, in the first we presented findings on impulsivity traits and PSU (papers 9 and 17), and included five effect sizes; the second was related to findings on neuroticism and problematic smartphone use, encompassing two effect sizes from papers 35 and 37. Random-effects models were applied in both cases as we found high levels of heterogeneity $\left(l^{2}=97.26 \%(p<.0001)\right.$ and $58.89 \%(p=.12)$ for impulsivity and neuroticism, respectively). The first random-effects analysis revealed an $r$ of .17 (95\% Cl: .04-.30), suggesting low relationship with a large spread considering the confidence intervals, and a high level of heterogeneity. Detailed results of the analysis are shown in Figure 2. 
Table 3. Quality Report and Bias Risk Assessment.

\begin{tabular}{|c|c|c|c|c|c|c|}
\hline Domain - Key & Key & 9 & 10 & 17 & 35 & 37 \\
\hline \multicolumn{7}{|c|}{ Quality report assessment } \\
\hline $\begin{array}{l}\text { Title and } \\
\text { abstract }\end{array}$ & $\begin{array}{l}\text { Title and } \\
\text { abstract }\end{array}$ & 1 & 1 & 1 & 1 & 1 \\
\hline \multirow[t]{2}{*}{ Introduction } & $\begin{array}{l}\text { Background/ } \\
\text { rationale }\end{array}$ & 1 & 1 & 1 & 1 & 1 \\
\hline & Objectives & 1 & 1 & 1 & 1 & 1 \\
\hline \multirow[t]{10}{*}{ Method } & Study design & 1 & 1 & 1 & 1 & 1 \\
\hline & Setting & 1 & 1 & 1 & 1 & 1 \\
\hline & Participants & 1 & 1 & 1 & 1 & 1 \\
\hline & Descriptive data & 1 & 1 & 1 & 0 & 1 \\
\hline & $\begin{array}{l}\text { Data } \\
\text { sources/measur } \\
\text { ement }\end{array}$ & 0 & 1 & 1 & 1 & 1 \\
\hline & $\begin{array}{l}\text { Description of } \\
\text { instruments }\end{array}$ & 0 & 1 & 1 & 1 & 0 \\
\hline & $\begin{array}{l}\text { Psychometric } \\
\text { properties } \\
\text { report }\end{array}$ & 0 & 1 & 1 & 1 & 0 \\
\hline & $\begin{array}{l}\text { Study sample } \\
\text { size }\end{array}$ & 0 & 0 & 0 & 0 & 0 \\
\hline & $\begin{array}{l}\text { Statistical } \\
\text { methods }\end{array}$ & 1 & 1 & 1 & 1 & 1 \\
\hline & Missing data & 1 & 1 & 1 & 1 & 1 \\
\hline Results & $\begin{array}{l}\text { Description of } \\
\text { results }\end{array}$ & 1 & 1 & 1 & 1 & 1 \\
\hline \multirow[t]{3}{*}{ Discussion } & Key results & 1 & 1 & 1 & 1 & 1 \\
\hline & Limitations & 1 & 1 & 1 & 0 & 1 \\
\hline & Interpretation & 1 & 1 & 1 & 0 & 1 \\
\hline Other & Generalizability & 1 & 1 & 1 & 1 & 1 \\
\hline \multirow[t]{2}{*}{ information } & Funding & 0 & 0 & 0 & 0 & 0 \\
\hline & $\begin{array}{l}\text { Journal Impact } \\
\text { Factor }\end{array}$ & $1(1.94)$ & $1(1.86)$ & $1(3.54)$ & $1(3.76)$ & $1(2.18)$ \\
\hline Total score & & $15(75 \%)$ & $18(90 \%)$ & $18(90 \%)$ & $15(75 \%)$ & $16(80 \%)$ \\
\hline \multicolumn{7}{|c|}{ Bias risk assessment } \\
\hline \multirow[t]{2}{*}{ Participants } & $\begin{array}{l}\text { Participants } \\
\text { description }\end{array}$ & 1 & 1 & 1 & 1 & 1 \\
\hline & Sample size & 1 & 1 & 1 & 1 & 1 \\
\hline Missing data & Missing data & 0 & 1 & 1 & 1 & 1 \\
\hline \multirow[t]{3}{*}{ Method } & $\begin{array}{l}\text { Psychometric } \\
\text { properties } \\
\text { detailing }\end{array}$ & 0 & 1 & 1 & 1 & 1 \\
\hline & Instruments & 1 & 1 & 1 & 1 & 1 \\
\hline & $\begin{array}{l}\text { Statistical } \\
\text { methods }\end{array}$ & 1 & 1 & 1 & 1 & 1 \\
\hline Total score & & $4(66.6 \%)$ & $6(100 \%)$ & $6(100 \%)$ & $6(100 \%)$ & $6(100 \%)$ \\
\hline
\end{tabular}

The second analysis, which verified the relationship of problematic smartphone use with neuroticism was conducted through a random-effects model. Figure 3 presents the details concerning the analysis.

We used the random-effects model even though the level of heterogeneity was not significant, because we had only two studies with large heterogeneity. The analysis showed an $r$ of .25 (95\% Cl: .11-.38), suggesting low to moderate relationship with some spread considering the confidence intervals. 


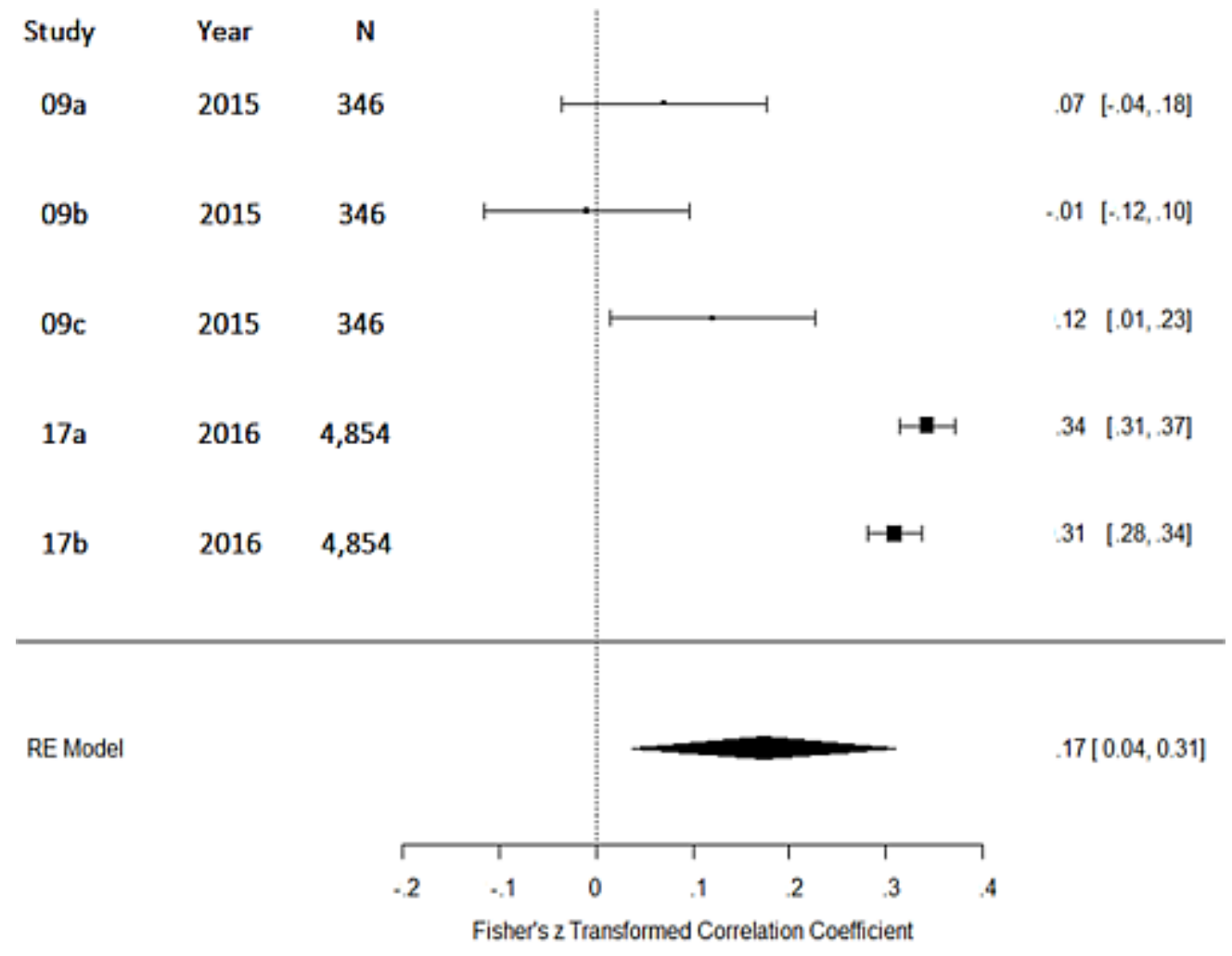

Test for heterogeneity: $\mathrm{Chi}^{2}=71.4633, \mathrm{df}=4(\mathrm{p}<.0001), \mathrm{I}^{2}=97.26 \%$

Test for overall effect size: $\mathrm{Z}=.17 / \mathrm{r}=.17, \mathrm{p}=.01$

Figure 2. Forest plot of meta-analysis on impulsivity and relationship with PSU.

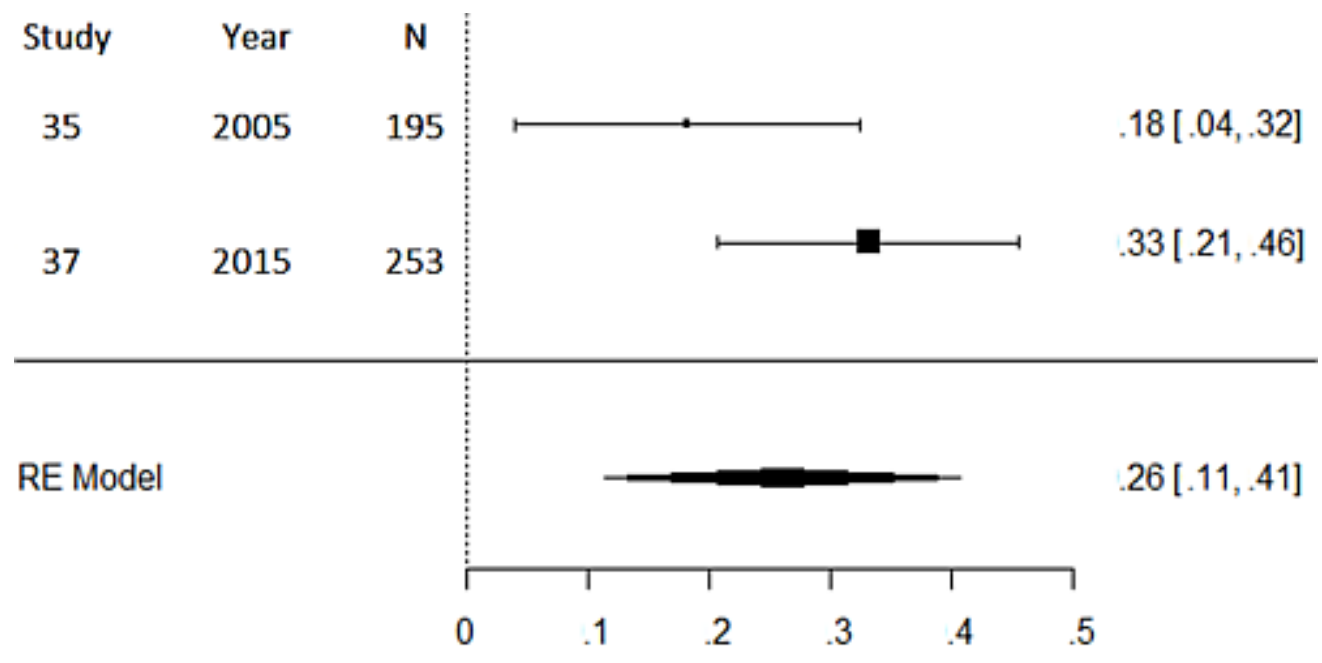

Fisher's z Transformed Correlation Coefficient

Test for heterogeneity: $\mathrm{Chi}^{2}=2.4325, \mathrm{df}=1(\mathrm{p}=.12), \mathrm{I}^{2}=58.89 \%$

Test for overall effect size: $Z=.26 / r=.26, p=.0005$

Figure 3. Forest plot of meta-analysis on neuroticism and its relationship with problematic smartphone use. 


\section{Discussion}

We aimed in this study to verify and aggregate empirical evidence from the literature concerning the relationship between PSU and pathological personality traits. In order to achieve this goal, we performed a systematic review and meta-analysis with a set of studies according to the currently established criteria, reflecting the specificities of the field. We did not find previous systematic reviews specifically addressing this issue. The use of systematic review to respond to a scientific problem assumes that an isolated study can lead to the biased conclusions, so that in a systematic review one actively sought to reduce bias by synthesizing all relevant studies to answer a given question (Holly, Salmond, \& Saimbert, 2012; Littell, Corcoran, \& Pillai, 2008; Petticrew \& Roberts, 2006). Therefore, the results of a systematic review should guide the next steps of a given area and present a conclusion based on what is already known to date.

Through the systematic review, we observed significant correlations between PSU and personality pathological traits, according to the 5 eligible studies, although the effect size of these relationships changed according to the pathological traits considered. The small number of studies in the area was expected, despite the evidence showing the relationship between PSU and mental health (Karaaziz \& Keskindag, 2015; Saidon et al., 2016; Torous et al., 2016). Based on the retrieved data, we can affirm that there is a relationship between PSU and pathological personality traits. In other words, people with pathological personality functioning tend to present more typical behaviors of PSU, although it should be considered that the effects found tended to be low. Nevertheless, considering that none of the studies used clinical samples, and samples specifically with personality disorders were not considered, we can hypothesize that the relationship between pathological traits and PSU are in fact more expressive, which was camouflaged by a decrease in the variability of the answers of the publications.

Moreover, depending on the data found in the studies, the impulsivity and neuroticism personality traits were considered for the meta-analysis. For impulsivity we found a low relationship with PSU scores, and for neuroticism, scores indicated a low to moderate correlation (Hemphill, 2003). In both cases, moderate to high levels of heterogeneity were observed, although for neuroticism the observed value was not significant.

Less than $1 \%$ of the studies found were selected, since the set of excluded studies addressed specific aspects related to smartphone use (e.g., which applications were accessed), but did not use a measure to assess PSU. Similarly, a larger number of studies evaluating healthy personality traits were found, compared to the amount of studies that used measures to evaluate pathological personality traits. Although the literature indicates to the relationship between PSU and psychopathology (e.g., Jenaro et al., 2007, Koivusilta et al., 2007), the previously reported scarcity of studies in this area (Kim et al., 2016; Roberts et al., 2015) was also observed in the present review. Maybe the small number of studies investigating the relationship between PSU and pathological personality traits reflects the early and exploratory stage of this area. A similar pattern can be observed in related areas, such as online social network relationship with personality traits (e.g., Carvalho \& Pianowski, 2017).

Among the five selected studies, the majority date from recent years, with $80 \%$ of the studies published after 2014 , which was also expected (Kim et al., 2016; Roberts et al., 2015). A growing curve regarding the studies relating the use of smartphones and psychological characteristics is an expected and necessary phenomenon, since the development of this technology is relatively new (i.e., beginning of the 21 st century) and the establishment of its use has recently reached unprecedented levels (Torous et al., 2016). In addition, a specific area of knowledge of the publications was not observed, and the authors mostly belonged to the departments of mental health, engineering, marketing, medical informatics, and social welfare. This heterogeneity is probably due to the knowledge involved in this area of study and should also reflect the widespread impact of using smartphone in the various contexts. We observed that most of the studies were published in different countries (e.g., $40 \%$ were from South Korea) and several journals (i.e., no journal had more than one publication), emphasizing the novelty of the field and its heterogeneity, not yet consolidated by any specific field of knowledge or country. The characteristics of the studies must be weighted considering the small number of studies included in this review.

Regarding the nomenclature used in the selected studies, different terms were applied to denominate PSU. The most used was smartphone addiction, accounting for $60 \%$ of studies. However, despite the diversity of terminology used, the literature demonstrates that the terms presently observed can be used as synonyms or are related to problematic smartphone use (Elhai et al., 2017). 
Specifically on the pathological personality traits, 12 distinct traits were investigated in the elected studies, and only five are typically pathological (i.e., Neuroticism, Impulsivity, Emotional instability, Psychoticism and Narcissism). The first two traits were investigated in more than one study ( $n=3$ and $n=2$, respectively). The choice of the pathological traits seems to have been guided by different reasons. The recurrent choice of the Neuroticism trait may be explained by the frequent use of the Five-Factor model, as explained previously. Also, both neuroticism and emotional instability traits are represented by characteristics such as vulnerability, anxiety, and tendency towards depression (Costa \& McCrae, 1992), which are typically associated to psychopathology in general. Indeed, the literature seems to corroborate the relationship of these personality traits and PSU (e.g., Beranuy, Oberst, Carbonell, \& Chamarro, 2009; Ha, Chin, Park, Ryu, \& Yu, 2008; Jenaro et al., 2007; Reid \& Reid, 2007). Regarding the contemplation of Impulsiveness in the studies, probably the very nature of the trait justifies the investigation of its relationship with the problematic use of technology, as people showing tendency towards problematic use tend to make decisions without worrying about the consequences, to be impulsive, and predisposed to addiction (Belin, Mar, Dalley, Robbins \& Everitt, 2008). Similarly, the psychoticism trait is related to aggressiveness, socially unacceptable behavior, sensation-seeking, and low impulse control, comprising some of the aspects of the impulsiveness trait, indicating a prior expectation to correlation with PSU, what was actually found (e.g., Mok et al., 2014). Finally, although the narcissistic trait has been considered only in one study, the literature reports that subjects with elevation in this trait tend to exhibit grandiosity, need for popularity, and need for attention (Lakey Rose, Campbell, \& Goodie, 2008; Rose, 2007, Stinson et al., 2009), which are characteristics typically related to the problematic and/or addictive use of technology. We also emphasize that some of these traits (e.g., neuroticism and impulsivity) have already been related to other addictive disorders such as drugs and Internet addiction (Belin et al., 2008; Bianchi \& Philips, 2005), associations that can be also expected by other manifestations of addictive behavior, as PSU.

Reflecting the theoretical frameworks previously proposed, as observed, impulsivity seems to be the trait of choice. For instance, the I-PACE (Brand, Young, Laier, Wölfling, \& Potenza, 2016) and the integrative model of Billieux (2012) include the impulsivity trait as one of the core characteristics that increase the probability of the individual shows PSU. Although neuroticism was also included in the Billieux model, it's not present in the I-PACE. Psychoticism and narcissism were not included in any of these models, probably because these models are not focused on personality disorders. According to our findings and theoretical frameworks, impulsivity and neuroticism seem to be promising, although specific pathological patterns (i.e., personality disorders) should also be investigated in the PSU context.

Specifically concerning the methodology and design of the selected studies, presented in Table 2 of this research, we observed that all studies were transversal. Although studies presenting a design that allows the control of variables of interest are desirable, in psychology and specifically in the field of interaction between psychology and technology use, cross-sectional designs are typically used, and some benefits can be observed. For instance, one of the elected studies (Kim et al., 2016) has a substantial sample size, which can render a robustness character to a cross-sectional study. Still in relation to the sample size, four studies had samples with less than 500 subjects $(M=310.5)$, and one study presented the smallest sample, published by Bianchi and Phillips (2005), probably due to the difficulty involved in the data collection, since the participants had to send back the envelope with the protocol responded to the researchers. Moreover, in none of the studies the rationale for the sample size was presented, which may signal a problem in the area, in which little attention to the importance of sample sizes are being given, and the sample sizes are strictly determined by the number of people the researcher can achieve within the deadline for data collection. In addition, most of the studies performed an online data collection $(n=3)$, which can be explained by the ease of the procedure, and because of the very focus of the research (i.e., technology encompassing internet).

Still on the sample characteristics, in all cases people were young ( $M_{\text {age }} \sim=36$ years), mostly composed by college students and women. One of the factors that probably contributed to the higher prevalence of young people in the studies is that older people may not use smartphones and, maybe more important, are not students at universities. However, there are data in the literature demonstrating that the use of technology can help to insert different target audiences in the surveys (Onnela \& Rauch, 2016). Thus, it is expected that in the future the studies will contemplate all age groups, not only because of the technology, but also for the very aging of the generations currently young. 
Another important limitation found in the eligible studies concerns the tools used for the assessment of levels of PSU and pathological personality traits. $40 \%$ of the studies included in the review did not provide sufficient information on the psychometric properties, nor was presented sufficient detail on the tools administered. These data do not necessarily mean that the tools used do not have adequate psychometric properties, but may suggest a downgrade in the importance given by researchers to the biases that assessment tools can bring to the studies.

About the assessment tools used in the elected studies, and specifically to the tests for PSU assessment, each study used a different instrument, demonstrating high heterogeneity, and four publications presented specific focus on the PSU assessment, although one (Bianchi \& Phillips, 2005) used a tool that also comprises social aspects of smartphone use. All the scales administered can be considered short (i.e., less than 40 items), but some variance was observed in relation to the total number of items (varying from 4 to 33 items), nevertheless, all presented adequate psychometric properties, when enough information was given, and have the same nature (i.e., selfreport). Three scales were developed more recently (from 2011) and two were created more than 10 years ago.

On the assessment tools for pathological personality traits, all of them were self-report, and presented adequate psychometric properties, when presented, with a variance of 15 to 79 items. Two instruments were applied in two studies, the Barratt Impulsiveness Scale (BIS) and The Eysenck Personality Questionnaire (EPQ). However, the latter presented different versions, and one study (Bianchi \& Phillips, 2005) used the revised short version. Among the six instruments presented in the studies, as seen in Table 2, only the BIS and the Dickman Dysfunctional Impulsivity Instrument (DDII) are strictly related to pathological aspects of personality (Cloninger, 1987; Costa \& McCrae, 1985; Dickman, 1990; Eysenck \& Eysenck, 1977; Fossati, Acquarini, \& Barratt, 2001; Zuckerman, 1979). Specially regarding the Narcissistic Personality Inventory (NPI), although several studies have appointed this test as an appropriate measure to assess narcissistic personality traits, there is evidence suggesting that its evaluation refers to healthier rather than pathological traits (Ackerman et al., 2011). Regarding the EPQ in both versions, despite not being a measure strictly for measuring pathological traits (e.g., extraversion), there are two factors related to pathological personality traits (i.e., neuroticism and psychoticism). For future studies we could expect a tendency towards the standardization on the choice of instruments for the assessment of pathological traits, allowing a more direct comparison between studies; and also a more specific choice of instruments that evaluates pathological traits (e.g., Personality Inventory for DSM-5; PID-5).

The results of the studies in this systematic review were also analyzed, seeking to verify possible patterns. In general, the effects of correlations seem to have a tendency towards being non-significant and to show low effect sizes, and similar results are also observed in the regression analyzes, albeit with slightly larger effects, probably due to the combined use of predictor variables. However, in the comparisons between groups the differences tended to be more expressive, possibly because the groups were artificially separated. Together, these data indicate that there are differences in relation to the pathological personality traits among people who experience PSU compared to people who do not. These differences can only be observed more expressively in the comparison between more extreme groups, and mainly for comparisons considering specifically women, but not for cases using only men (e.g., Mok et al., 2014). However, it should be considered that none of the studies considered psychiatric patients in the samples and, as discussed earlier, some of the assessment tools administered are focused on healthy traits more than pathological traits, which may lead to some loss in the assessment of psychopathological functioning.

The combination of the results presented in the eligible studies do not allow the establishing of a pathological personality profile more susceptible to manifest PSU, as not all studies encompassed all pathological traits presently discussed. Nevertheless, the analysis of the selected studies suggests that people showing higher levels in the narcissism and emotional instability traits are more likely to manifest problematic smartphone use when compared to people with low levels on these traits. Something similar can be stated to the neuroticism and impulsivity traits, but to a lesser extent for the case of neuroticism (i.e., weaker relationship) and greater variability in the studies for the case of impulsivity (i.e., greater inconsistency). Based on these findings, we can hypothesize that people with a personality profile characterized by an increase in more than one of these traits should be even more likely to manifest PSU. Future studies should seek to evaluate these traits in the same sample, allowing for testing this hypothesis. 
The meta-analysis effect size indicated greater relationship of PSU with neuroticism in comparison to the impulsivity trait. Despite the low correlations observed, even when the $\mathrm{Cl}$ was considered, some overall effect can be observed. Probably the correlation with the impulsivity trait was lower because the assessment scales are more extreme, i.e., the impulsivity scales are more related to pathological levels, representing atypical traits in the general population. Future studies should seek to verify if the effects of correlations tend to increase in samples including clinical samples. Although neuroticism presents a higher correlation with PSU, only two studies were included in the meta-analysis, and therefore the data should be considered with caution. Nevertheless, all the studies obtained moderate to high scores in the quality report assessment and high scores in the bias risk verification, showing sufficient quality in terms of information presented and methodological design.

From the findings of this review we suggest that professionals, as clinicians, consider the smartphone use as a potential maladjustment related to pathological traits. For instance, patients showing addictive behaviors to smartphone, should be evaluated on neuroticism and impulsivity. Although our findings are not focused on interventions, we can hypothesize that procedures to reduce the levels on these traits could also help in diminishing the smartphone related-problems. Moreover, theoretical models, as I-PACE, can be used as basis for understanding the patients' functioning.

Some limitations of the present review must be considered. The first limitation concerns the sensitivity of the search strategy and the inclusion and exclusion criteria applied. As the focus was given to the pathological personality traits, it is possible that some relevant studies have been excluded in the screening or some studies may not have been retrieved in the search. Second, some of the results presented in the elected studies were not considered for meta-analysis, which made it impossible to further integrate the data. Third, although we have reviewed all studies indicating the account of any pathological personality trait, one must consider that, in some level, selection studies accounting pathological traits is somewhat arbitrary, as any traits per se can be considered healthy or pathologic. Fourth, two methodological choices were arbitrary: selecting solely the first 10 pages of the Google Scholar, and only the journals presenting an impact factor of .75 or higher. Maybe these choices hid some relevant publications in the field.

Although one should consider that the effects found tended to be low, we can assert that people with pathological personality functioning tend to have more typical behaviors of PSU. Maybe the associations between pathological traits and PSU are more expressive, but were decreased in function of the low variability on the scores of the pathological traits measures. Future studies should verify this hypothesis, including clinical samples diagnosed with personality disorders. Furthermore, meta-analysis indicated that narcissism and emotional instability traits are associated with PSU behaviors; neuroticism and impulsivity traits are also associated, but the evidences were weaker. As a suggestion for future research, studies encompassing several pathological traits (e.g., traits presented in the criterion B of the DSM-5 section III; American Psychiatric Association, 2013) and clinical samples with personality disorders should be conducted seeking to deepen the understanding of the association of pathological traits with PSU.

\section{Supplement}

Supplementary material with the 36 references excluded after full reading is available here.

\section{References}

\section{* denotes a reference among the reviewed studies}

Ackerman, R. A., Witt, E. A., Donnellan, M. B., Trzesniewski, K. H., Robins, R. W., Kashy, D. A. (2011). What does the Narcissistic Personality Inventory really measure? Assessment, 18, 67-87.

https://doi.org/10.1177/1073191110382845

American Psychiatric Association. (2013). Diagnostic and statistical manual of mental disorders (5 $5^{\text {th }}$ ed.). Washington, DC: Author. 
Belin, D., Mar, A. C., Dalley, J. W., Robbins, T. W., \& Everitt, B. J. (2008). High impulsivity predicts the switch to compulsive cocaine taking. Science, 320, 1352-1355. https://doi.org/10.1126/science.1158136

Beranuy, M., Oberst, U., Carbonell, X., \& Chamarro, A. (2009). Problematic Internet and mobile phone use and clinical symptoms in college students: The role of emotional intelligence. Computers in Human Behavior, 25, 11821187. https://doi.org/10.1016/j.chb.2009.03.001

*Bianchi, A., \& Phillips, J. G. (2005). Psychological predictors of problem mobile phone use. CyberPsychology and Behavior, 8, 39-51. https://doi.org/10.1089/cpb.2005.8.39

Billieux, J. (2012). Problematic use of the mobile phone: a literature review and a pathways model. Current Psychiatry Reviews, 8, 299-307. http://dx.doi.org/10.2174/157340012803520522

Borenstein, M., Hedges, L. V., Higgins, J. P. T., \& Rothstein, H. R. (2009). Introduction to meta-analysis. Chichester: Jonn Wiley \& Sons.

Brand, M., Young, K. S., Laier, C., Wölfling, K., \& Potenza, M. C. (2016). Integrating psychological and neurobiological considerations regarding the development and maintenance of specific Internet-use disorders: An Interaction of Person-Affect-Cognition-Execution (I-PACE) model. Neuroscience and Biobehavioral Reviews, 71, 252-266. https://doi.org/10.1016/j.neubiorev.2016.08.033

Carvalho, L. F., \& Pianowski, G. (2017). Pathological personality traits assessment using Facebook: Systematic review and meta-analyses. Computers in Human Behavior, 71, 307-317. https://doi.org/10.1016/j.chb.2017.01.061

Cazzulino, F., Burke, R. V., Muller, V., Arbogast, H., \& Upperman, J. S. (2014). Cell phones and young drivers: A systematic review regarding the association between psychological factors and prevention. Traffic Injury Prevention, 15, 234-242. https://doi.org/10.1080/15389588.2013.822075

Cloninger, C. R. (1987). A systematic method for clinical description and classification of personality variants. Archives of General Psychiatry, 44, 573-588. https://doi.org/10.1001/archpsyc.1987.01800180093014

Costa, P. T., \& McCrae, R. R. (1985). The NEO personality inventory manual. Odessa, FL: Psychological Assessment Resources.

Costa, P. T., \& McCrae, R. R. (1992). Revised NEO Personality Inventory (NEO-PI-R) and NEO Five-Factor Inventory (NEO-FFI) manual. Odessa, FL: Psychological Assessment Resources.

Davey, J., Turner, R. M., Clarke, M. J., \& Higgins, J. P. T. (2011). Characteristics of meta-analyses and their component studies in the Cochrane Database of Systematic Reviews: A cross-sectional, descriptive analysis. BMC Medical Research Methodology, 11(160). https://doi.org/10.1186/1471-2288-11-160

De Pasquale, C., Sciacca, F., \& Hichy, Z. (2015). Smartphone addiction and dissociative experience: An investigation in Italian adolescents aged between 14 and 19 years. International Journal of Psychology \& Behavior Analysis, 1(109). http://dx.doi.org/10.15344/2455-3867/2015/109

Demirci, K., Akgönül, M., Akpinar, A., 2015. Relationship of smartphone use severity with sleep quality, depression, and anxiety in university students. Journal of Behavioral Addictions 4, 85-92.

https://doi.org/10.1556/2006.4.2015.010

Demirhan, E., Randler, C., \& Horzum, M. B. (2016). Is problematic mobile phone use explained by chronotype and personality? Chronobiology International. The Journal of Biological and Medical Rhythm Research, 33, 821-831. https://doi.org/10.3109/07420528.2016.1171232

Dickman, S. J. (1990). Functional and dysfunctional impulsivity: Personality and cognitive correlates. Journal of Personality and Social Psychology, 58, 95-102. https://doi.org/10.1037/0022-3514.58.1.95

Elhai, J. D., Dvorak, R. D., Levine, J. C., \& Hall, B. J. (2017). Problematic smartphone use: A conceptual overview and systematic review of relations with anxiety and depression psychopathology. Journal of Affective Disorders, 207, 251-259. https://doi.org/10.1016/j.jad.2016.08.030 
Elhai, J. D., Tiamiyu, M. F., Weeks, J. W., Levine, J. C., Picard, K. J., \& Hall, B. J. (2018). Depression and emotion regulation predict objective smartphone use measured over one week. Personality and Individual Differences, 133, 21-28. https://doi.org/10.1016/j.paid.2017.04.051

Eysenck, S. B. G., \& Eysenck, H. J. (1977). The place of impulsiveness in a dimensional system of personality. British Journal of Social and Clinical Psychology, 16, 57- 68. http://dx.doi.org/10.1111/j.2044-8260.1977.tb01003.x

Fossati, A., Acquarini, A. C. E., \& Barratt, E. S. (2001). Psychometric properties of an Italian version of the Barratt Impulsiviness Scale - 11 (Bis-11) in nonclinical subjects. Journal of Clinical Psychology, 57, 815-828.

Gutiérrez, J, D., Fonseca, F. R., \& Rubio, G. (2016). Cell-phone addiction: A review. Frontiers in Psychiatry, 7(175). https://doi.org/10.3389/fpsyt.2016.00175

Ha, J. H., Chin, B., Park, D. H., Ryu, S. H., \& Yu, J. (2008). Characteristics of excessive cellular phone use in Korean adolescents. CyberPsychology \& Behavior, 11, 783-784. https://doi.org/10.1089/cpb.2008.0096

Haug, S., Castro, R. P., Kwon, M., Filler, A., Kowatsch, T., \& Schaub, M. P. (2015). Smartphone use and smartphone addiction among young people in Switzerland. Journal of Behavioral Addictions, 4, 299-307.

https://doi.org/10.1556/2006.4.2015.037

Hemphill, J. F. (2003). Interpreting the magnitudes of correlation coefficients. American Psychologist, 58, 78-80. https://doi.org/10.1037/0003-066X.58.1.78

Holly, C., Salmond, S. W., \& Saimbert, M. K. (2012). Comprehensive systematic review for advanced nursing practice. New York, NY: Springer.

Jenaro, C., Flores, N., Gómez-Vela, M., González-Gil, F., \& Caballo, C. (2007). Problematic internet and cell-phone use: Psychological, behavioral, and health correlates. Addiction Research \& Theory, 15, 309-320.

https://doi.org/10.1080/16066350701350247

Karaaziz, M., \& Keskindag, B. (2015). "I love my smartphone": A review study of smartphone addiction and related psychological risk factors. Bağımlılık Dergisi - Journal of Dependence, 16(2), 78-85.

Kardefelt-Winther, D. (2014). A conceptual and methodological critique of internet addiction research: Towards a model of compensatory internet use. Computers in Human Behavior, 31, 351-354.

https://doi.org/10.1016/j.chb.2013.10.059

Kardefelt-Winther, D., Heeren, A., Schimmenti, A., van Rooij, A., Maurage, P., Carras, M., . . Billieux, J. (2017). How can we conceptualize behavioural addiction without pathologizing common behaviours? Addiction, 112, 17091715. https://doi.org/10.1111/add.13763

*Kim, Y., Jeong, J. E., Cho, H., Jung, D. J., Kwak, M., Rho, M. J., . . Choi, I. Y. (2016). Personality factors predicting smartphone addiction predisposition: Behavioral inhibition and activation systems, impulsivity, and self-control. PLOS ONE, 11(8). https://doi.org/10.1371/journal.pone.0159788

Kim, J., Seo, M., \& David, P. (2015). Alleviating depression only to become problematic mobile phone users: Can face-to-face communication be the antidote? Computers in Human Behavior 51, 440-447.

https://doi.org/10.1016/j.chb.2015.05.030

Koivusilta, L. K., Lintonen, T. P., \& Rimpelä, A. H. (2007). Orientation in adolescent use of information communication technology: A digital divide by sociodemographic background, educational career, and health. Scandinavian Journal of Public Health, 35, 95-103. https://doi.org/10.1080/14034940600868721

Kuss, D., Griffiths, M., Karila, L., \& Billieux, J. (2014). Internet addiction: A systematic review of epidemiological research for the last decade. Current Pharmaceutical Design, 20, 4026-4052.

Kwon, M., Lee. J. Y., Won, W. Y., Park, J. W., Min, J. A., Hahn, C., . . Kim, D. J. (2013). Development and validation of a Smartphone Addiction Scale (SAS). PLoS ONE, 8(2). https://doi.org/10.1371/journal.pone.0056936

Lachmann, B., Duke, É., Sariyska, R., \& Montag, C. (2017). Who's addicted to the smartphone and/or the internet? Psychology of Popular Media Culture. https://doi.org/10.1037/ppm0000172 
Lakey, C., Rose, P., Campbell, W., \& Goodie, A. (2008). Probing the link between narcissism and gambling: The mediating role of judgment and decision-making biases. Journal of Behavioral Decision Making, 21, 113-137. https://doi.org/10.1002/bdm.582

Lanaj, K., Johnson, R. E., \& Barnes, C. M. (2014). Beginning the workday yet already depleted? Consequences of late-night smartphone use and sleep. Organizational Behavior and Human Decision Processes, 124, 11-23. https://doi.org/10.1016/j.obhdp.2014.01.001

Lane, W., \& Manner, C. (2011). The impact of personality traits on smartphone ownership and use. Internacional Journal of Business and Social Science, 2(17), 22-28.

Lee, Y., Chang, C., Lin, Y., \& Cheng, Z. (2014). The dark side of smartphone usage: Psychological traits, compulsive behavior and technostress. Computers in Human Behavior, 31, 373-383. https://doi.org/10.1016/j.chb.2013.10.047

Lee, J., Sung, M., Song, S., Lee, Y., Cho, S., Park, M., \& Shin, Y. (2016). Psychological factors associated with smartphone addiction in south Korean adolescents. The Journal of Early Adolescence, 38. 1-15.

http://dx.doi.org/10.1177/0272431616670751

Lepp, A., Li, J., Barkley, J. E., \& Salehi-Esfahani, S. (2015). Exploring the relantionships between College student's cell phone use, personality and leisure. Computers in Human Behavior, 43, 210-219.

https://doi.org/10.1016/j.chb.2014.11.006

Lin, Y-H., Chiang, C-L., Lin, P-H., Chang, L-R., Ko, C-H., Lee, Y-H., \& Lin, S-H. (2016). Proposed diagnostic criteria for smartphone addiction. PLOS ONE, 11(11). https://doi.org/10.1371/journal.pone.0163010

Littel, H. J., Corcoran, J., \& Pillai, V. (2008). Systematic reviews and meta-analysis. Oxford: Oxford university press.

Lopez-Fernandez, O. (2017). Short version of the Smartphone Addiction Scale adapted to Spanish and French: Towards a cross-cultural research in problematic mobile phone use. Addictive Behaviors, 64, 275-280.

https://doi.org/10.1016/j.addbeh.2015.11.013

Millon, T. (2016). What is a personality disorder? Journal of Personality Disorders, 30, 289-306.

Moher, D., Liberati, A., Tetzlaff, J., \& Altman, D. (2009). Preferred reporting items for systematic reviews and meta-analyses: The PRISMA statement. Annals of Internal Medicine, 151, 264-269.

https://doi.org/10.1371/journal.pmed.1000097

*Mok, J-Y., Choi, S-W., Kim, D-J., Choi, J-S., Lee, J., Ahn, H., . . Song, W-Y. (2014). Latent class analysis on internet and smartphone addiction in college students. Neuropsychiatric Disease and Treatment, 10, 817-828.

https://doi.org/10.2147/NDT.S59293

Montag, C., Błaszkiewicz, K., Lachmann, B., Andone, I., Sariyska, R., Trendaflov, B., . . Markowetz, A. (2015). Correlating personality and actual phone usage: evidence from psychoinformatics. Journal of Individual Differences, 35, 158-165. http://dx.doi.org/10.1027/1614-0001/a000139

Montag, C., \& Reuter, M. (2017). Molecular genetics, personality, and internet addiction revisited. In C. Montag \& M. Reuter (Eds.), Internet addiction: Neuroscientific approaches and therapeutical implications including smartphone addiction (pp. 141-160). Switzerland: Springer.

Moons, K. G. M., Groot, J. A. H., Bouwmeester, W., Vergouwe, Y., Mallett, S., Altman, D., . . Collins, G. S. (2014). Critical appraisal and data extraction for systematic reviews of prediction modelling studies: The CHARMS Checklist. PLoS Med, 11(10). https://doi.org/10.1371/journal.pmed.1001744

Mueller, A., Claes, L., Mitchell, J. E., Faber, R. J., Fischer, J., \& Zwaan, M. (2011). Does compulsive buying differ between male and female students? Personality and Individual Differences, 50, 1309-1312.

https://doi.org/10.1016/j.paid.2011.02.026

Onnela, J. P., \& Rauch, S. L. (2016). Harnessing smartphone-based digital phenotyping to enhance behavioral and mental health. Neuropsychopharmacology, 41, 1691-1696. http://dx.doi.org/10.1038/npp.2016.7 
Oulasvirta, A., Rattenbury, T., Ma, L., \& Raita, E. (2012). Habits make smartphone use more pervasive. Personal and Ubiquitous Computing, 16, 105-114. https://doi.org/10.1007/s00779-011-0412-2

Panova, T., \& Carbonell, X. (2018). Is smartphone addiction really an addiction? Journal of Behavioral Addictions, 7 , 252-259. https://doi.org/10.1556/2006.7.2018.49

*Pearson, C., \& Hussain, Z. (2015). Smartphone use, addiction, narcissism, and personality: A mixed methods investigation. International Journal of Cyber Behavior, Psychology and Learning, 5(1), 17-32.

https://doi.org/10.4018/ijcbpl.2015010102

Peterson, R. A., \& Brown, S. P. (2005). On the use of beta coefficients in meta-analysis. Journal of Applied Psychology, 90, 175-181. https://doi.org/10.1037/0021-9010.90.1.175

Petticrew, M., \& Roberts, H. (2006). Systematic reviews in the social sciences: A practical guide. Malden: Blackwell publishing.

Radovic, A., Vona, P. L., Santostefano, A. M., Ciaravino, S., Miller, E., \& Stein, B. D. (2016). Smartphone applications for mental health. CyberPsychology \& Behavior, 19, 465-470. https://doi.org/10.1089/cyber.2015.0619

Rainie, L., \& Wellman, B. (2012). Networked: The New Social Operating System. Cambridge, MA: MIT.

Reid, D. J., \& Reid, F. J. M. (2007). Text or talk? Social anxiety, loneliness, and divergent preferences for cell phone use. CyberPsychology \& Behavior, 10, 424-435. https://doi.org/10.1089/cpb.2006.9936

Roberts, J., \& Pirog, S. (2013). A preliminary investigation of materialism and impulsiveness as predictors of technological addictions among young adults. Journal of Behavioral Addictions, 2, 56-62.

https://doi.org/10.1556/JBA.1.2012.011

*Roberts, J. A., Pullig, C., \& Manolis, C. (2015). I need my smartphone: A hierarchical model of personality and cell-phone addiction. Personality and Individual Differences, 79, 13-19. https://doi.org/10.1016/j.paid.2015.01.049

Rose, P. (2007). Mediators of the association between narcissism and compulsive buying: The role of materialism and impulse control. Psychology of Addictive Behaviors, 21, 567-581. http://dx.doi.org/10.1037/0893-164X.21.4.576

Rothstein, H. R., Sutton, A. J., \& Borerenstein, M. (1996). Publication bias in meta-analysis: Prevention, assessment and adjustments. Chichester: John Wiley \& Sons.

Rozgonjuk, D., Rosenvald, V., Janno, S., \& Täht, K. (2016). Developing a shorter version of the Estonian Smartphone Addiction Proneness Scale (E-SAPS18). Cyberpsychology: Journal of Psychosocial research on Cyberspace, 10(4), article 4. https://doi.org/10.5817/CP2016-4-4

Rozgonjuk, D., Saal, K., \& Täht, K. (2018). Problematic smartphone use, deep and surface approaches to learning, and social media use in lectures. International Journal of Environmental Research and Public Health, 15(1), article 92. https://doi.org/10.3390/ijerph15010092

Saidon, J., Musa, R., Harun, M. H. M., \& Adam, A. A. (2014) Exploring the attributes of Pathological Smartphone Use (PSU). In M. Abdullah, W. Yahya, N. Ramli, S. Mohamed, \& B. Ahmad (Eds.), Regional Conference on Science, Technology and Social Sciences (RCSTSS 2014) (pp. 215-223). Singapore: Springer.

Samaha, M., \& Hawi, N. S. (2016). Relationships among smartphone addiction, stress, academic performance, and satisfaction with life. Computers in Human Behavior, 57, 321-325. https://doi.org/10.1016/j.chb.2015.12.045

Sarwar, M., \& Soomro, T. R. (2013). Impact of smartphone's on society. European Journal of Scientific Research, 98, 216-226.

Scimago Lab. (2016, January). SCImago Journal \& Country Rank. Retrieved from: http://www.scimagojr.com/

Statista Inc. (2016). Number of smartphone users worldwide from 2014 to 2020 (in billions). Retrieved from https://www.statista.com/statistics/330695/number-of-smartphone-users-worldwide/ 
Stinson, F., Dawson, D., Goldstein, R., Chou, S., Huang, B., Smith, S., ... Grant, B. F. (2009). Prevalence, correlates, disability, and comorbidity of DSM-IV narcissistic personality disorder: Results from the wave 2 national epidemiological survey on alcohol and related conditions. The Journal of Clinical Psychiatry, 69, 1033-1045. https://doi.org/10.4088/JCP

Sutton, A. J., \& Abrams, K. R. (2000). Methods for meta-analysis in medical research. Chichester: John Wiley \& Sons.

Takao, M., Takahashi, S., \& Kitamura, M. (2009). Addictive personality and problematic mobile phone use. CyberPsychology \& Behavior, 12, 501-507. https://doi.org/10.1089/cpb.2009.0022

Toda, M., Ezoe, S., Mure, K., \& Takeshita, T. (2016). Relationship of smartphone dependence to general health status and personality traits among university students. Open Journal of Preventine Medicine, 6, 215-221. https://doi.org/10.4236/ojpm.2016.610020

Torous, J., Kiang, M. V., Lorme, J., \& Onnela, J. P. (2016). New tools for new research in psychiatry: A scalable and customizable platform to empower data driven smartphone research. JMIR Mental Health, 3, e16. https://doi.org/10.2196/mental.5165

Turner, R. M., Bird, S. M., \& Higgins, J. P. T. (2013). The impact of study size on meta-analyses: Examination of underpowered studies in Cochrane reviews. PLOS ONE, 8(3). https://doi.org/10.1371/journal.pone.0059202.g001

Ünal, P., Temizel, T. T., \& Eren, P. E. (2016). Impact of individual differences on the use of mobile phones and applications. In M. Younas, I. Awan \& M. Mecella (Eds.), Mobile web and intelligent information systems (pp. 379392).

Viechtbauer W. (2017). Package "metafor" for R software. Institute for Statistics and Mathematics. Retrieved from: https://cran.r-project.org/web/packages/metafor/metafor.pdf

von Elm, E., Altman, D. G., Egger, M., Pocock, S. J., Gøtzsche, P. C., \& Vandenbroucke, J. P. (2007). The Strengthening the Reporting of Observational Studies in Epidemiology (STROBE) statement: Guidelines for reporting observational studies. BMJ, 335, 806-808. https://doi.org/10.1136/bmj.39335.541782.AD

Wang, J. L., Wang, H. Z., Gaskin, J., \& Wang, L. H. (2015). The role of stress and motivation in problematic smartphone use among college students. Computers in Human Behavior, 53, 181-188.

https://doi.org/10.1016/j.chb.2015.07.005

Wang, D., Xiang, Z., \& Fesenmaier, D. R. (2014). Adapting to the mobile world: A model of smartphone use. Annals of Tourism Research, 48, 11-26. https://doi.org/10.1016/j.annals.2014.04.008

Yogesh, S., Abha, S., \& Priyanka, S. (2014). Mobile usage and sleep patterns among medical students. Indian Journal of Physiology and Pharmacology, 58, 100-103.

Zuckerman, M. (1979). Sensation-seeking: Beyond the optimal level of arousal. Hillsdale, NJ: Erlbaum.

\section{Correspondence to:}

Lucas F. Carvalho

Universidade São Francisco

R. Waldemar César da Silveira 5

Jardim Cura D'Ars

Campinas 13045-510

São Paulo

Email: lucas(at)labape.com.br

Editorial record: First submission received on May 23, 2018. Revisions received on September 27, 2018, and November 15, 2018. Accepted for publication on November 25, 2018. 


\section{About Authors}

Lucas de Francisco Carvalho, (Ph.D. Universidade São Francisco, Psychology Department, 2011) is Assistant Professor at the Department of Psychology at Universidade São Francisco in Brazil. Lucas Carvahlo's research interests include online social network, particularly focusing on pathological traits and personality disorders.

Catarina P. Sette, (Master Universidade São Francisco, Psychology Department, 2015) is Ph.D. student at the Department of Psychology at Universidade São Francisco in Brazil. Catarina Sette's research interests include online social network, particularly focusing on fear of missing out (FoMO) and Facebook addiction behavior.

Bárbara Letícia Ferrari, (Master Universidade São Francisco, Psychology Department, 2017). Bárbara Ferrari's research interests is focused on online social network, specifically, Facebook and smartphone addiction. 